\title{
THE FINANCING OF R\&D: CHALLENGES FOR ROMANIAN FIRMS
}

\author{
Mihaela Diaconu \\ “Gheorghe Asachi” Technical University of Iaşi \\ mhl_dcn@yahoo.fr
}

\begin{abstract}
This paper provides a review regarding the financing issues of innovative firms in Romania. The financing resources used by innovative firms are closely interdependent with innovation modes adopted by firms ( $R \& D$ and non-R\&D innovations). In the context I highlight the difficulties in attracting external funding resources and the implications for government policy. In this respect, I begin by describing some of the unique features of R\&D investments. Then I discuss the various theoretical arguments why external finance for $R \& D$ might be more expensive than internal finance, going on to review statistical evidence on the support of this hypothesis and the solutions that have to be developed and adopted by the government. The paper concludes with a discussion of policy options.
\end{abstract}

\section{Keywords}

innovation; firm; business angels; venture capital; debt financing

\section{JEL Classification}

O31; G24; M41

\section{Introduction}

Innovation is a source of competitiveness and economic development. Research and development (R\&D) is considered to be an important input of innovation and industrial production. The financing conditions of innovative firms and the issues they face in attracting external financial resources for R\&D projects create a framework for government policy intervention. In order to shape the specific framework regarding the financing of innovative firms, I tried to answer two questions: What does reflect the financing resources used by the Romanian firms from the perspective of their innovative projects? Which are the solutions that can be adopted by the government to spur R\&D innovations in Romania?

Our concern for the ways of financing of innovative firms in this country is justified given the very modest size of the input indicators (BERD/GDP and GERD/GDP) in the period 2000-2012 that are influenced by the industrial structure (with a prevalence of low-tech industries and non-R\&D innovations) and non-innovative small and medium sized enterprises. In the same time, the innovation expenditure structure reflects the lowest implication in internal $R \& D$ activity and allocating funding resources mainly to machines, production equipment and software by the innovative firms (Diaconu, 2012, 2013).

Romania is situated far below the EU 27 with respect to R\&D expenditure. This gap is due mainly to the $R \& D$ expenses made in the enterprises sector that we found being also at a statistically significant unfavorable and persistent difference from the EU 27. The imperative of increasing $R \& D$ expenditure can be observed as a result of a poor performance obtained from innovation in Romania. From this point of view, the orientation of innovation by stimulating the enterprises to engage themselves more in 
research must be able to attenuate the considerable vulnerabilities that hinder the economic development based on knowledge: the concentration of economic and creative capacities in several sectors and the industry dependence on the imports of technologies, on the external resources of knowledge and the insufficient funding from venture capital.

In this paper I briefly review in section 2 the characteristics of R\&D projects and their impact on funding resources. The financing of innovative firms in Romania is discussed in section 3 according with data available and section 4 concludes with a discussion of policy options.

\section{R\&D projects characteristics and the impact on the funding resources}

Viewed as an investment projects, R\&D activities present distinctive characteristics from investments in real assets impacting the use of financing resources. First of all, R\&D projects incorporate significant amount of funds for remuneration of researchers and engineers; their efforts to increase knowledge are source of profit for the firm through the development of new products and processes. Training expenses and staff salaries are smoothed over time, implying significant adjustment costs for firms (Hall, 2009, 2010). Secondly, R\&D has higher income but more uncertain. Investment is made over a long period of time, during which new information reduces uncertainty and it requires an analysis of projects throughout the lifetime. Another feature of $\mathrm{R} \& \mathrm{D}$ projects corresponds to the creation of intangible capital partly incorporated in human capital with low salvage value, presenting implications on the project financing. R\&D reduces the size of the company's fixed assets while increasing the level of investment in research which implies sunk costs as R\&D commitments grow. In principle, firm can use retained earnings, debt and equity for funding $R \& D$ projects. One may admit that firms choose funds such that the financial structure involves minimizing the cost of capital. Economic theories (Jaffe \& Russell, 1976; Stiglitz \& Weiss, 1981; Myers \& Majluf, 1984) suggest a higher cost of external financing supported by firms due to the information asymmetry between the innovator and investor and to the tax incidence. The aspects associated to information asymmetry have gained particular attention, being more grounded in practice as the pecking order hypothesis is identified to be at a greater relevance in designing firms' financial structure. Firms adopting R\&D project will have far better knowledge of the cost and payoffs than the financier, explaining information asymmetry (or incomplete information) and credit rationing phenomena. Even in the absence of credit rationing, asymmetric information issues may determine external debt and equity to be more expensive than internally available funds leading to underinvestment.

The SME (small and medium-sized enterprise) sector is the most affected by the credit rationing as it is characterized by a greater variability of profits and growth than large companies. As a result, SMEs are focused on obtaining funds from informal resources and thus appear to be less linked to the formal market trends related to stable income. The use of internal funds or quasi-equity (loans from family or friends) implies incurring a required rate of return below the market level, while (formal) loans from banks can be contracted at an interest rate above the average rate of the financial market, and possibly higher than that supported by large enterprises.

A subset of the SMEs that require special considerations relate to the innovative ones, that are more important for the national economy and operate, in principle, independently of bank financing. These SMEs have an innovative behavior in creating competitive advantage and growth. They differ from other SMEs aiming at progress and growth through innovation. Unlike traditional SMEs that adopt tested 
products or services and rapidly obtain positive cash-flows, a dynamic (innovative) firm will start by incorporating new concepts and marketing methods. In general, innovative SMEs may be identified as enterprises that operate in high-tech sectors although, in this context can be incorporated other firm as well, with a significant proportion of R\&D expenses of the total turnover. After going through characteristic stages, these companies will record growing revenues, absorb labor, export goods and services and register high productivity, but the possibility of funding is a precondition for establishment and development of these firms.

In the case of innovative SMEs, capacity of financing is crucial for entrepreneurial success. The main difficulties supported by innovators in accessing financial resources include the cost of capital which incorporates the risk premium required by capital suppliers, agent and moral hazard costs, lack of collateral associated with intangible assets, lack of track record and limited market potential. Traditional sources of financing such as bank loans, including those guaranteed by government or stock issues on the traditional stock exchanges are of the limited relevance for the innovative SMEs, in their confrontation with initial negative cash flows, untested business models and uncertainty of business success. Start-up and small firms face, in principle, with the most severe financial constraints due to the greater intensity of information asymmetry. In principle, after the company exceeded its early stages, it becomes a potential candidate for venture capital investments that link the firm with institutional capital sources. The financing from venture capital minimizes the informational gap as the firm's access depends on an adequate business plan and demonstrates potential commercial success. A reduced access to the traditional external resources limits funding and threatens innovative companies to grow. Venture capitals are, generally, considered to be the most appropriate financial resources for technologically innovative SMEs. Venture capital firms do not only provide resources for the financing of projects, but give also experience in research activities and diffusion of innovations, shaping the company's business strategy.

\section{The financing of innovative firms in Romania}

In order to assess the severity of financial constraint on innovation, most empirical studies aimed at reflecting cost differences between internal and external financing. In this respect, $R \& D$ expenditure is used as a proxy for innovation expenditure in different investment equations following the economic theory. It is not surprising that most studies show that innovative SMEs are the most affected by the phenomenon of financial constraint. An issue unexplained in the literature refers to the nature of the funding gap, especially at the innovative SMEs level, knowing that they are more affected by financial constraints than large firms. One can admit that a funding gap exists if firms cannot get funds they need because of market imperfections. Although identifying funding gap is of interest to government policy in the implementation of appropriate measures to support innovation, the difficulty of distinguishing between the existing and the perceived gap remains unsolved since there is no conclusive evidence determining whether the supply or demand gap prevails in innovative SME (Bank of England, 2001).

In order to reflect the financing difficulties faced by SMEs is essential to have statistical data. Community Innovation Survey (CIS) centralizes data on factors that hamper innovation, but only up to the CIS 2008 (for the interval 2004-2008). In figure 1 we present obstacles perceived by firms in Romania to innovate, all NACE sectors. The figure 1 shows that innovative firms claim lack of internal funding and this shapes the main obstacle. Most affected, in this respect, appear to be the innovative 
ones and small firms (< 50 employees) with a proportion of $34.80 \%$ who lack their own resources. This obstacle diminishes as enterprise grows; lack of internal funds register medium enterprises with $24.79 \%$ of the total (50 - 249 employees) and large firms with $24.19 \%$ of the total (> 250 employees).

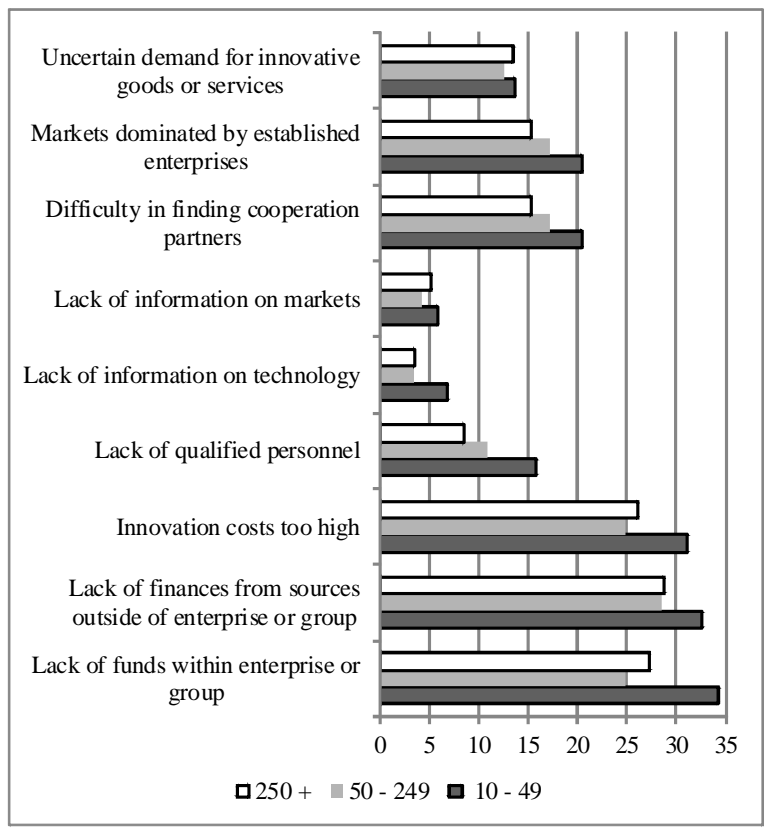

Figure 1 Obstacles perceived by Romanian innovative firms, all sectors Source: Community Innovation Survey (CIS 2008) - Eurostat database

The next most important obstacles in innovation are the lack of external financial resources and the cost of innovation. Non-innovative firms express similar proportions of those lacking their own funds and confront with obstacles of comparable intensity (CIS 2008 - Eurostat database).

Higher financing obstacles faced by small businesses confirm the theory predictions. From this perspective, it is not surprisingly that, using The World Bank Enterprise Survey data, we showed that small firms prefer internal funds that are mostly used for investments, having a lower proportion of bank loans in the financial structure. At the same framework, new equity is another important resource for small enterprises and its use is reduced with increasing the firm's size (Diaconu, 2013).

The particular interest in EU to monitor the development of SMEs in Europe determined that the SMEs finance database (European Commission \& European Central Bank) to be improved by increasing the number of questions regarding many aspects that characterize SMEs funding in the survey. This does not incorporate only innovative firms, and responses refer also to financing innovation by using venture capital and firms' perceptions regarding their use. We have chosen two questions the most representative for our study for the Romanian SMEs from the year 2012, making possible a comparison with responses in the EU 27 (figures 2 and 3).

The firm's preference for a given external funding resource may reflect its availability and/or an attractive cost. In this respect, figure 2 shows that all firms opt for bank 
loans, loans from other sources, but equity including venture capital and business angels funds have a much smaller representation. Although the preference of Romanian firms for debt, despite the highest interest rate in Europe supported, would seem to be a paradox, this fact may reflect, to a large extent, that there are no other financial resources available for innovation on the financial market. In figure 3 we see that the size of the interest rate is considered to be the biggest obstacle by $33.70 \%$ of SMEs in Romania in using debt (against 19.3\% of the total SMEs at the EU average). This perceived obstacle is followed by the insufficient collateral or guarantees.

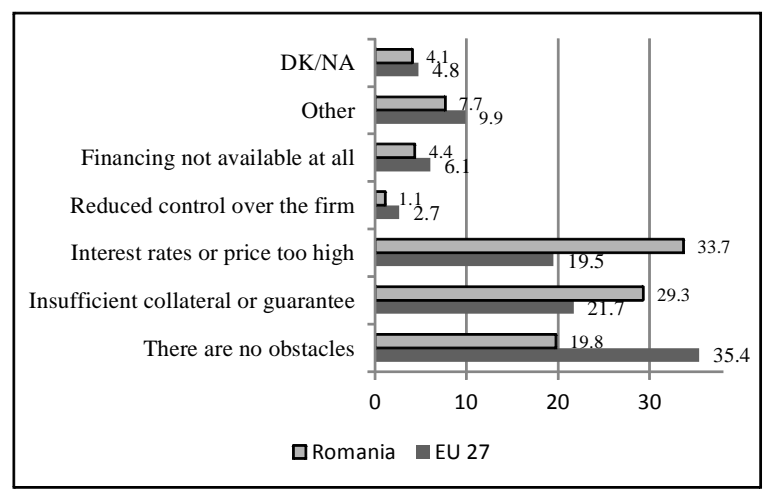

Figure 2 External funds preferred by SMEs

Source: Access to finance for SMEs in the euro area - European Commission database

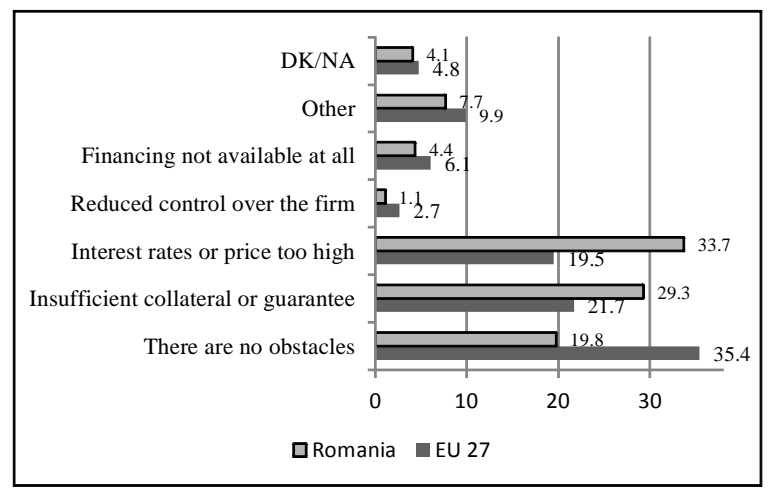

Figure 3 Obstacles faced by SMEs in attracting preferred external financing

Source: Access to finance for SMEs in the euro area - European Commission database

The SME sector, as in the EU, most of the economic activity generates a higher level of revenues than large firms (turnover ratio is greater than 60\%). Despite the satisfactory performance of SMEs, the economy suffers from lack of dynamic SMEs, especially in high-tech sectors that could stimulate competitiveness and development by generating of technologies. The low proportion of firms in sectors with low R\&Dintensity explains their preference for bank loans. Firms preference for loans and for a reduced use of equity investment (including venture capital) is, at the same time, a consequence of encouraging debt financing, the dominance of banks in the financial system in Romania, an inadequate culture of funding by equity and venture capital. 
Highlighting the funding gap through the poor demand for funds coming from innovative firms or, the supply gap reflecting non-available funds for innovation allows formulating appropriate policy measures to spur innovation. Beyond the obvious usefulness of questionnaires regarding the financing resources used by firms, there are limits to their use in terms of lack of control groups for comparison (noninnovative/innovative firms) and such analysis cannot reflect the failure of different entrepreneurs to innovate or start a business. However, the low proportion of innovative companies focused on R\&D activities, significant cost of bank loans and the weak representation of venture capital in the financing innovation denotes both a demand and a low supply of innovation funding, mainly in the early stages.

Despite the positive incidence in the economy, the size of private equity market, including venture capital, varies considerably over time in the European space. Viewed as a whole, the investment activity in the Central and East-European countries (CEE) showed a similar trend of other EU countries, but the investment size was much smaller, representing less than $3 \%$ of the total investments made in the EU. In fact, the venture capital industry in this region is still a young one, with a continuous development since its inception. As in previous years, the investment activity in this region in 2010-2012 was concentrated mainly in Poland. The size of venture capital invested in the early stages was the lowest and this characteristic has been maintained in the CEE market.

The concentration of venture capital invested especially in the expansion stage and buyout also is a characteristic of Romanian market in the period 2000-2012 (figure 4). Investments in the early stages have been sporadic and maintained at a level between $0-15 \%$ of the total venture capital invested (15\% being recorded in 2002). Even if the share of investments in expansion and buyout is dominant, its irregular and volatile evolution persists. Investments targeted mainly to the stages of expansion and buyout demonstrate obtaining of more attractive returns at a lower risk profiles to investors in these stages than in early (seed and start-up) stages of the small enterprises. We can admit that the later ones have been adversely affected by the lack of financing due to the absence of the (visible) market segment of individual investors (business angels) and of venture capital firms. Small and new innovative firms experience high costs of capital that are not mitigated by the presence of venture capital.

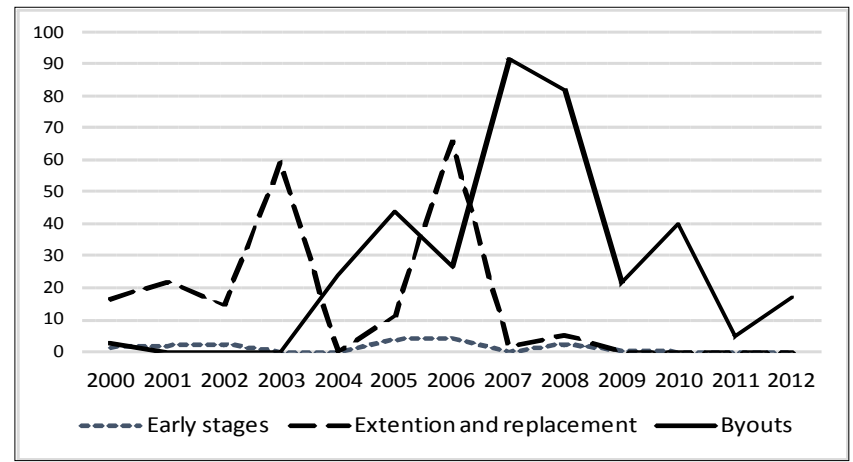

Figure 4 Private equity investments in Romania (mil. of euros)

Source: Eurostat database (2000-2012)

In general, investments in Romania have been concentrated mainly in the life sciences sectors where $49.8 \%$ of the total investment has been carried out (in the year 2010), in 
communications $-14.9 \%$, consumer products, services and retail $-13.6 \%$, energy and environment $-9.7 \%$ etc. High-tech sectors have been registered sporadic investments, reflecting the effects of the industrial structure (these accounted for 5.6 per cent of the total investment in 2009, 56.60\% in 2006 and $0 \%$ in the other years).

Funds raised and divestments showed also large oscillations reflecting the fragility of the private equity market in Romania. This feature is even more evident the more funds raised, for example, in 2006-2011, came from European government agencies (external funds counted more than $90 \%$ of the total), while investors such as pension funds, funds of funds, insurance companies and banks have been absent from the capital providers spectrum in recent years, being inclusively the consequence of a poor adapted regulatory framework for making high risk investments. In the same time, divestments have been performed mainly through trade sales of the companies to strategic investors and not through initial public offering (IPO) - regarded as the signal of a successful venture capital process in terms of yields achievable by venture capital firms and investors. This has been the dominant divestment mode to unlocking capital, obtaining earnings and their subsequent reinvestments.

In the literature, existing studies on the determinants of venture capital investment activity in various countries aimed at identifying the factors with potential impact on the investment level and proceed to constructing of indicators to reflect their incidence, followed by testing them in econometric equations (Gompers \& Lerner, 1998; Poterba, 1989; Jeng \& Wells, 2000; Romain \& van Pottelsberghe, 2004; Clarysse et al, 2009; Cherif \& Gazdar, 2011; etc.). Generally, such factors can be regarded as cyclical, such as GDP growth rate or, structural - the entrepreneurial activity and culture formed in the R\&D field, the capital market activity, the institutional environment and taxation on corporate income or on capital gains etc. We tested various factors with impact on the equilibrium amount of venture capital invested in Romania in the period 2000-2010, including in the equation the annual GDP growth rate, the stock market capitalization, the real long-term interest rate, the gross expenditure on R\&D (GERD) to GDP, the effective marginal tax rate on capital income and the unemployment rate (Diaconu, 2012b). We could not incorporate the aspects of institutional environment that also would have been of importance for our analysis, due to difficulties to capture and quantify them without having the necessary statistical data. However, the absence of the private pension funds as sources of institutional savings, at least until the year 2007, could shape another explanation of the modest size of venture capital invested in Romania. In addition, we have pointed out the restrictions imposed to the pension funds to invest in unlisted companies, the lack of tax incentives to promote innovative young firms, to conduct research activities, technology transfer and cooperation contracts between enterprises and higher education or research institutions. Our results indicate that the total $R \& D$ intensity is the main determinant of the venture capitals invested in this period in the two phases (for early stages and expansion). A significant incidence, mainly on the supply side, also shows the annual long term real interest rate, while the market capitalization, the effective marginal tax rate on corporate income, the annual inflation or unemployment rate do not impact on the venture capital. In terms of forming and developing of the venture capital market, our recommendation concerns strengthening the demand for funds, respectively encouraging of enterprises to innovate, creating of conditions for the supply to be manifested in the seed and startup stages and the compatibilization of the need for financial resources with prudential rules by adapting regulations for institutional investors. 


\section{Conclusions and policy implications}

A number of conclusions have emerged from our theoretical and empirical work. These are consistent across the various samples and methodological approaches. It was important to emphasize the market failures catalogued here due to the separation of financier and entrepreneur. First, debt is not a favored funding source for R\&D projects. Second, stock market in Romania is undeveloped and exhibit weak sensitivity and responsiveness to R\&D and firms' cash flow. Third, the weak responsiveness may arise not because firms are not financial constrained, but due to the low cash-flow devoted to R\&D projects. Finally, there is now considerable evidence that young and/or small firms are more likely to face financial constraints than large established firms and presumably they invest less in R\&D. High costs of capital is not mitigated by the presence of business angels or venture capital. In fact, investments made by venture capitalists in Romania, in absolute and relative amount (as a proportion of GDP), has been one of the lowest in comparison with the EU average in the period 2000-2012, with a clear investment tendency to the expansion phase of the enterprises. The absence of individual investors (business angels) and almost no supply of venture capital coming from in institutional investors to the early stages have been a major impediment to the development of the R\&D intensive industries. Abandoning the $\mathrm{R} \& \mathrm{D}$ projects due to the lack of funding cannot be captured by the venture capital variation to the ratio of business expenditure on R\&D (BERD) to GDP.

Venture capital investment activity in the two (early stage and expansion) segments is influenced mainly by the total R\&D intensity. This result has important implications for the government policy given the role of venture capital in the economy. In this respect, stimulating the supply of venture capital requires, first of all, strengthening the demand of funds by boosting enterprises to innovate and development of attractive projects, through implementing direct and indirect mechanisms to support access to the research results funded from government sources, including the transfer of the research results to business sector to be valued. In the same context, supporting the supply of funds in seed and start-ups stages uncovered by the intermediated market of venture capital becomes essential and it is able to meet the demand for funds of these stages. Since the success of each stage of innovative firm depends on the ability perceived to progress to the next stage, appropriate funding mechanisms are needed for each stage. However, increasing the financial resources for innovation cannot be achieved by limiting pension funds to invest. Elimination of the restrictive ceiling may be able to provide financial resources for innovative firms and raising the expected returns of funds through harmonizing investment risk with anticipated profitability.

\section{References}

Bank of England (2001), Financing of Technology-Based Small Firms, available on http://www. bankofengland.co.uk.

Cherif, M., Gazdar, K. (2011), What Drives Venture Capital in Europe? New Results from a Panel Data Analysis, Journal of Applied Business and Economics, 12(3), 122-139.

Clarysse, B., Knockaert, M., Wright, M. (2009), Benchmarking UK venture capital to the US and Israel: what lessons can be learned?, Report prepared for the British Private Equity and Venture Capital Association (BVCA).

Diaconu, M. (2013), Incidenţa fiscalităţii asupra inovării tehnologice, in Păun, I. O., Ionescu, C., Dinga, E. (ed.), Studii post-doctorale în Economie. Disertații post- 
doctorale, Volume 3, Studii și cercetări fiscal-bugetare, Bucharest, Publishing House of the Romanian Academy, 270-349.

Diaconu, M. (2012a), Performance paradigms in the innovation activity: the case of Romania, Actual Problems of Economics, 9(135), 292-302.

Diaconu, M. (2012b), Characteristics and drivers of venture capital investment activity in Romania, Theoretical and Applied Economics, Volume XIX, 7(572), 111-132.

Hall, B. (2010), The Financing of Innovative Firms, Review of Economics and Institutions, 1(1), 1-30.

Hall, B. (2009), The Financing of R\&D and Innovation, NBER Working Paper 15325, Cambridge MA: NBER.

Gompers, P., Lerner, J. (1998), What drives venture fundraising?, Brookings Papers on Economic Activity, Microeconomics, 149-192.

Jaffe, A., Russell, T. (1976), Imperfect information, uncertainty and credit rationing, Quarterly Journal of Economics, 90, 651-666.

Jeng, L. A., Wells, P. C. (2000), The Determinants of Venture Capital Funding: Evidence across countries, Journal of Corporate Finance, 6, 241-289.

Myers, S., Majluf, N., (1984), Corporate financing and investment decisions when firms have information that investors do not have, Journal of Financial Economics, 13(2), 187-221.

Poterba, J. (1989), Venture capital and capital gains taxation, in Summers, L. (ed.) Tax Policy and the Economy, MIT Press Cambridge MA.

Romain, A., van Pottelsberghe, B. (2004), The determinants of venture capital: a panel analysis of 16 OECD countries, Discussion paper, 19, Universite Libre de Bruxelles.

Stiglitz, J., Weiss, A. (1981), Credit Rationing in Markets with Incomplete Information, American Economic Review, 71, 393-409. 